\title{
ГИДРАВЛИЧЕСКИЙ РАСЧЕТ ПРОТИВОПОЖАРНЫХ ТРУБОПРОВОДОВ В АНАЛИТИЧЕСКОМ КОМПЛЕКСЕ «АЭРОСЕТЬ»
}

\author{
М.Д. Попов, Д.С. Кормщиков \\ Горный институт УрО РАН, г. Пермь
}

\begin{abstract}
Аннотация: На сегодняшний день проведение инженерных расчетов с использованием специализированных вычислительных комплексов является обязательным требованием действующих в нашей стране правил безопасности. Одним из необходимых применительно к действующим шахтам и рудникам является расчет пожарно-оросительного водоснабжения, в настоящее время реализованный в аналитическом комплексе «Аэросеть». В статье описаны особенности построения математических моделей системы шахтных трубопроводов. Описан алгоритм, применяемый при гидравлическом расчете. Также в статье уделяется внимание способам анализа результатов моделирования, позволяющим разрабатывать технические решения как на стадии проектирования, так и на стадии эксплуатация рудника.

Ключевые слова: пожарно-оросительный трубопровод, гидравлический расчет, математическое моделирование, графический анализ, гидравлическое сопротивление, шахта, рудник, АэроСеть.
\end{abstract}

\section{Введение}

На данный момент количество легкодоступных полезных ископаемых, находящихся в благоприятных горно-геологических условиях, значительно сокращается. Горнодобывающие предприятия вынуждены расширять площади отрабатываемых участков месторождений и переходить на глубокозалегающие горизонты для поддержания или увеличения производственных мощностей. С увеличением площади отрабатываемых участков и глубины ведения горных работ возрастает протяженность сетей горных выработок, рабочие зоны перемещаются на границы шахтного поля [1]. Дополнительным неблагоприятным фактором является повышение температуры стенок горных выработок и ухудшение микроклиматических условий в рабочих зонах $[2,3]$.

Сопутствующим фактором, накладывающим дополнительные требования на надежность системы противопожарного водоснабжения, является значительное увеличение протяженности сетей электроснабжения [4] и рост количества применяемого шахтного оборудования. Совокупность вышеперечисленных факторов увеличивает возможность возникновения аварийных ситуаций, связанных с пожаром.

Таким образом, особое внимание должно уделяться системе пожарно-оросительного водоснабжения, которая является основным и наиболее эффективным звеном противопожарной защиты в подземных условиях $[5,6]$.

С точки зрения отмеченных выше факторов закономерным является требование пункта 26 Федеральных норм и правил «Инструкция по локализации и ликвидации последствий аварий на опасных производственных объектах, на которых ведутся горные работы» о том, что расчеты параметров противопожарного водоснабжения должны производиться с использованием специального программного обеспечения на основе моделей топологии горных выработок. Следует отметить, что на данный момент конфигурация сетей пожарно-оросительного трубопровода достаточно сложна. Под усложнением конфигурации понимается следующее:

- наличие большого количества колец с целью резервирования отдельных участков сети;

- наличие нескольких независимых источников;

- применение подземных повысительных насосных станций

Данные особенности делают гидравлический расчет систем противопожарного водоснабжения без использования специализированных программ практически невозможным $[7,8]$. 
Также следует отметить, что любое значительное изменение схемы прокладки трубопроводов и ввод нового насосного оборудования приводит к абсолютно новому гидравлическому режиму. В условиях постоянного изменения положения участков добычи полезного ископаемого и соответственно потребителей, оперативное проектирование и пересчет системы водоснабжения является вынужденной мерой, необходимой для проверки обеспеченности потребителей требуемым расходом и напором.

Основными параметрами, определяемыми в ходе численного решения задачи гидравлического расчета пожарно-оросительных трубопроводов на стадии проектирования и эксплуатации, являются:

- полное давление воды на концах трубопровода и в местах подключения потребителей;

- требуемые рабочие точки насосного оборудования;

- расходы воды в местах расположения потребителей;

- места установки повысительных насосных станций.

В последние годы для проведения гидравлических расчетов все более широкое применение находят отечественные и зарубежные программные комплексы; к наиболее известным из которых относятся «АэроСеть» [9], «Вентиляция 2.0» [10] и «VentSim» [11].

Аналитический комплекс «АэроСеть» разрабатывается специалистами Горного института Уральского отделения Российской академии наук. Основными задачами, решаемыми в данном комплексе, традиционно являются задачи рудничной вентиляции и теплофизики. Однако в настоящее время в перечень решаемых задач также стали входить задачи гидравлического расчета пожарно-оросительных трубопроводов.

В данной статье представлены основные функциональные возможности аналитического комплекса «АэроСеть» при расчетах пожарно-оросительных трубопроводов в шахтах и рудниках.

\section{Создание математической модели}

На начальном этапе для проведения гидравлического расчета необходимо построить трехмерную топологию сети горных выработок. Так как в программе «Аэросеть» по умолчанию считается, что трубопровод всегда располагается внутри горной выработки, то чаще всего для построения гидравлической сети используются топология вентиляционной модели.

Для ускорения процесса построения модели в программе «Аэросеть», кроме отрисовки горных выработок с использованием фонового изображения и задания свойств каждого элемента вручную, предусмотрен ряд следующих инструментов:

- импорт топологии из горно-геологических информационных систем (ГГИС); импорт сети выработок возможен из широко применяемых форматов .dxf, xml и .csv.

- наличие возможности создания справочников типов отдельных элементов модели, характеризующихся одинаковым диаметром, толщиной стенки и коэффициентом шероховатости (рис. 1); применение созданных типов позволяет применять групповые свойства сразу к группе объектов, например для задания свойств магистральных и распределительных трубопроводов.

- использование справочников, хранящихся в программе для загрузки параметров насосного оборудования и коэффициентов для разных типов материалов труб. (рис. 2). 


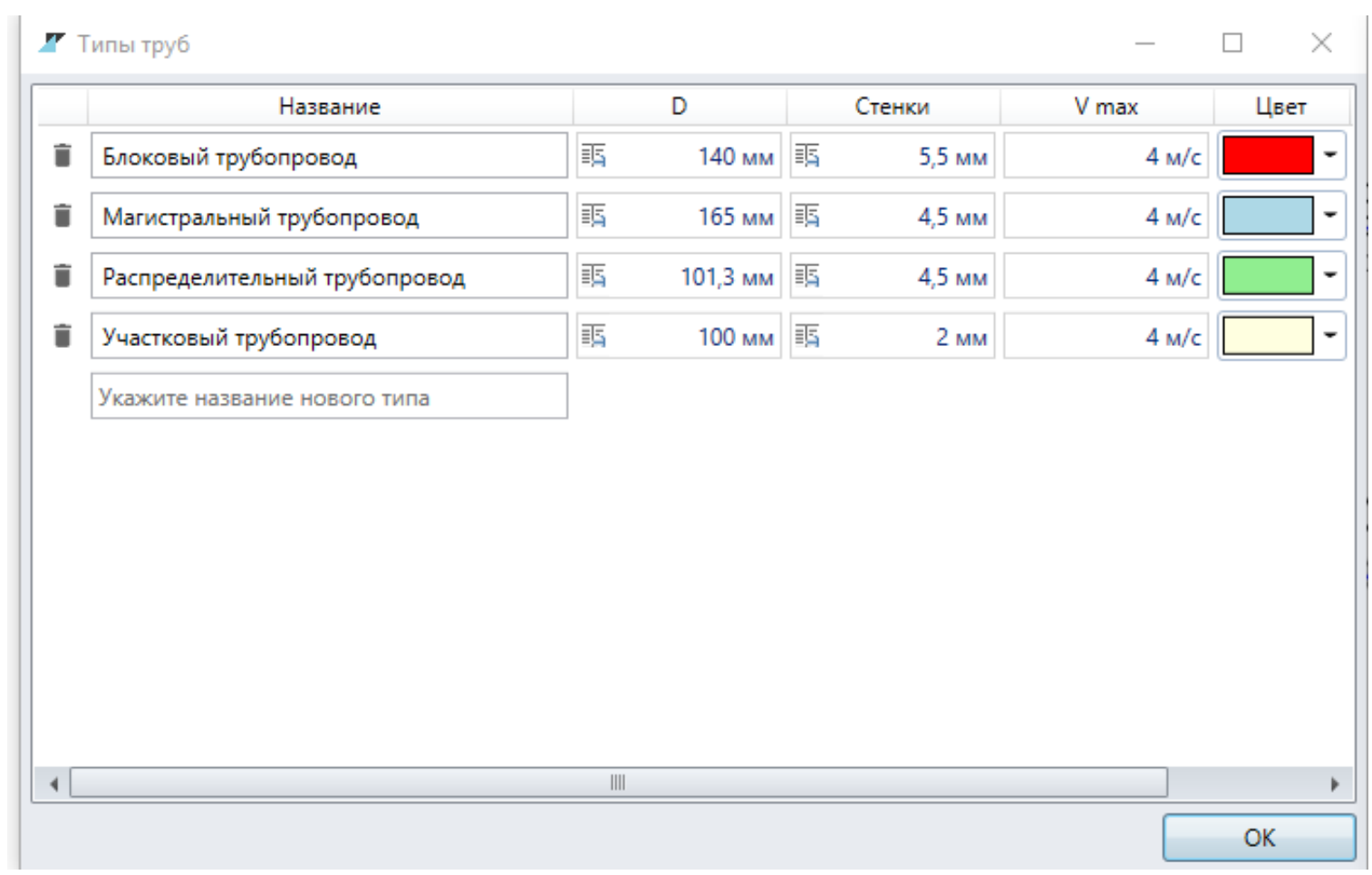

Рис. 1. Рабочее окно программы «АэроСеть», окно справочника типовых участков трубопровода

На готовой топологии сети горных выработок отмечаются возможные места отбора воды и источник водоснабжения. У каждого потребителя воды в свойствах указывается требуемый расход воды, а также информация о том, активен потребитель или нет.

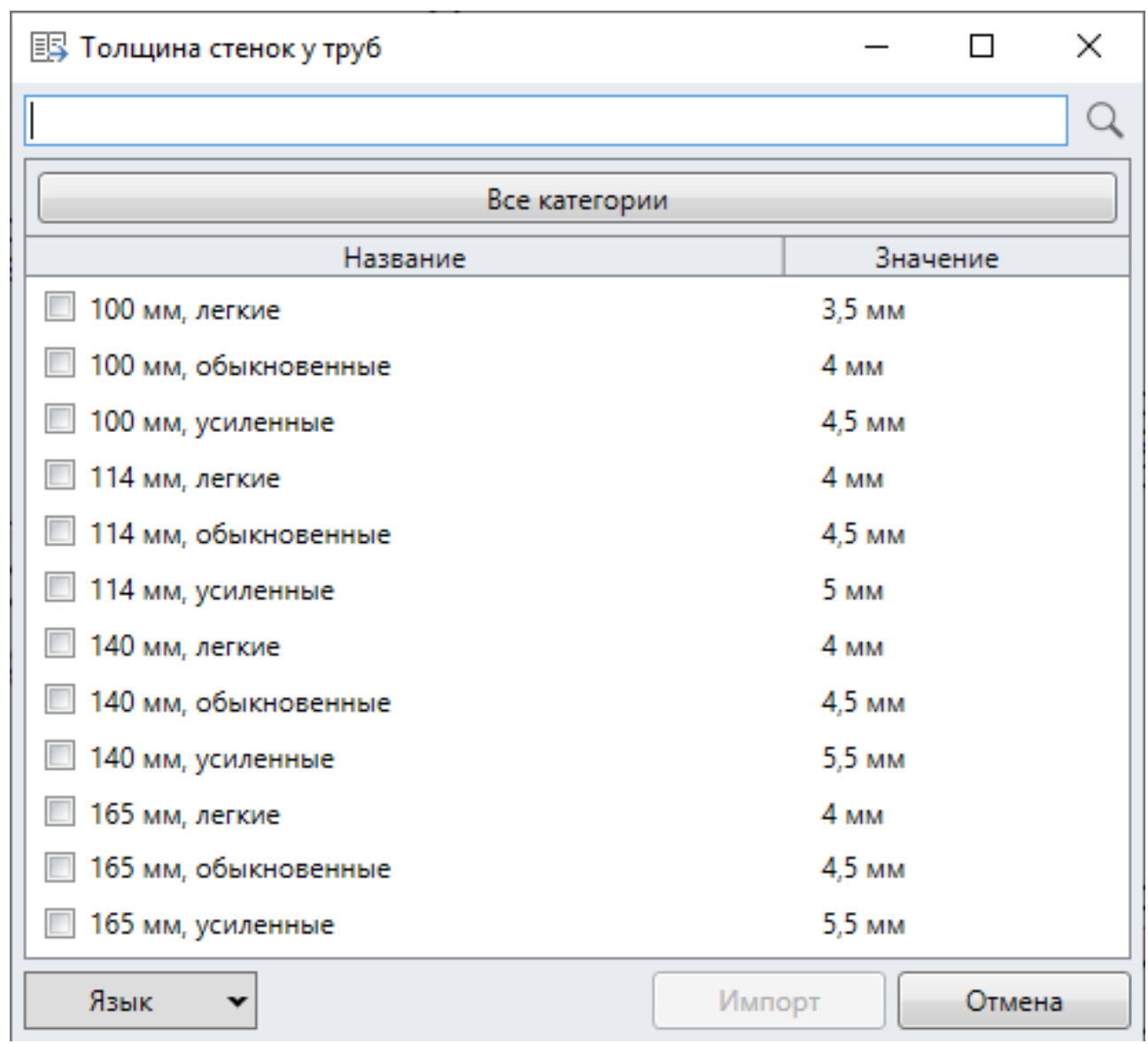




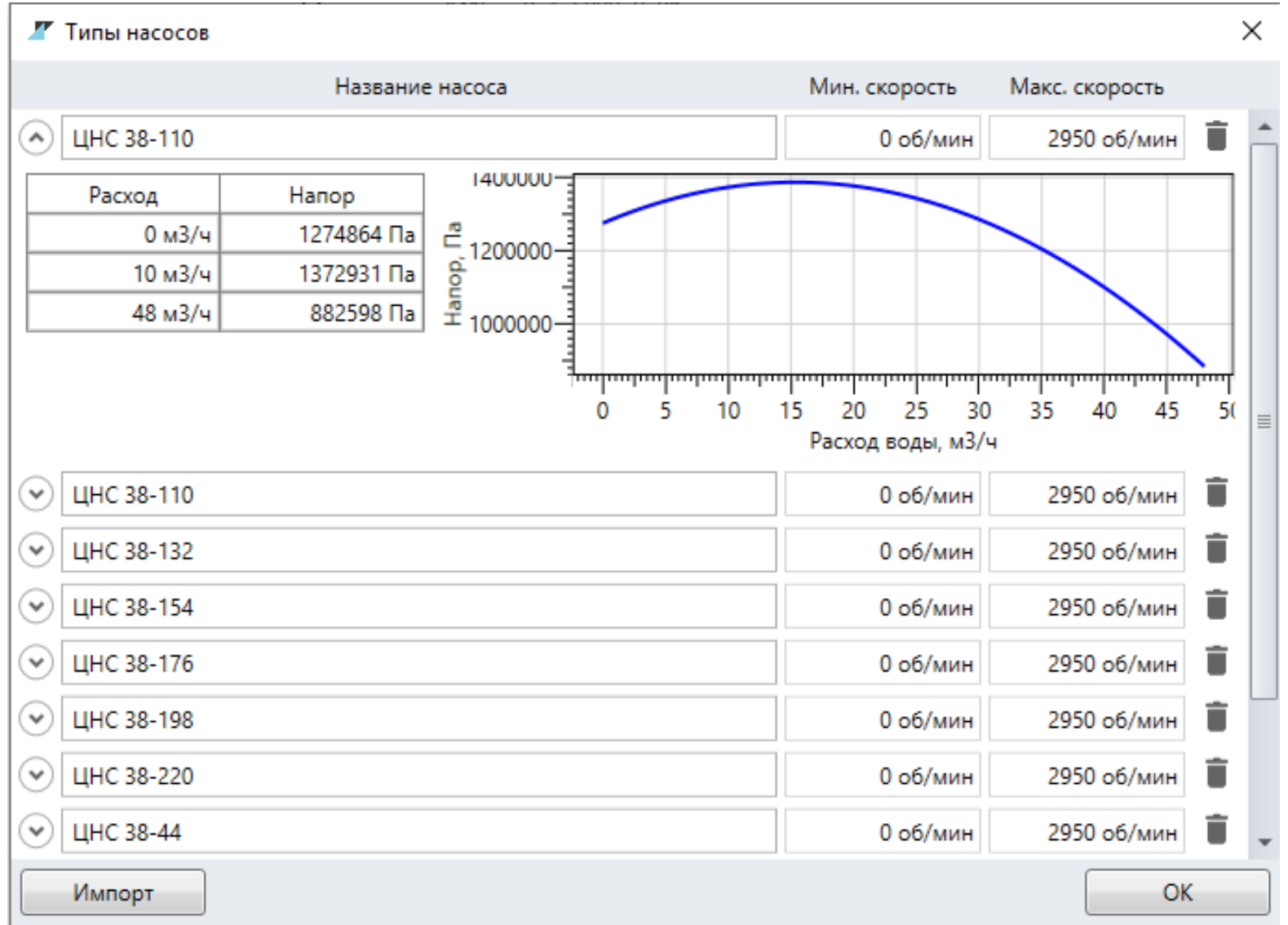

Рис. 2. Рабочее окно программы «АэроСеть», окно справочника напорных характеристик насосного оборудования и справочника типов труб

В конечном счете пользователь программы работает с трехмерной моделью, содержащей топологию горных выработок с нанесенными на нее трубопроводами, конечными потребителями, запорной арматурой и насосным оборудованием (рис. 3).

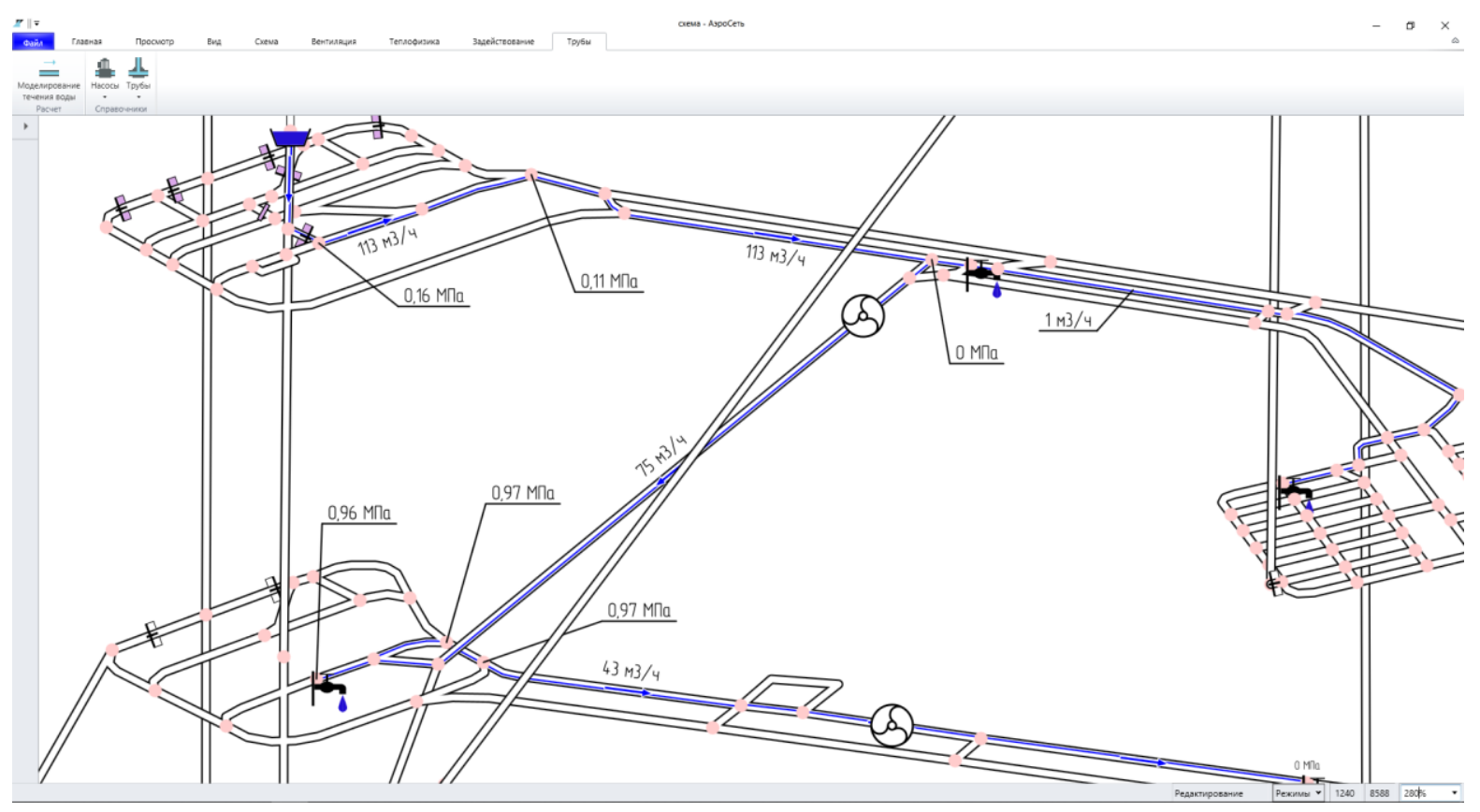

Рис. 3. Пример совмещенной трехмерной модели гидравлической и вентиляционной сети рудника «Таймырский» (часть подсечных горизонтов «-1050 м» и «-1100 м») 
После того, как построена топология системы водоснабжения и определены места установки запорной арматуры, потребителей и насосного оборудования, программа произведет гидравлический расчет (рис. 4). Задача гидравлического расчета заключается в определении следующих параметров:

- расход и скорости воды на каждом участке сети;

- давление во всех узловых точках и на конечных потребителях;

- рабочие токи насосного оборудования.

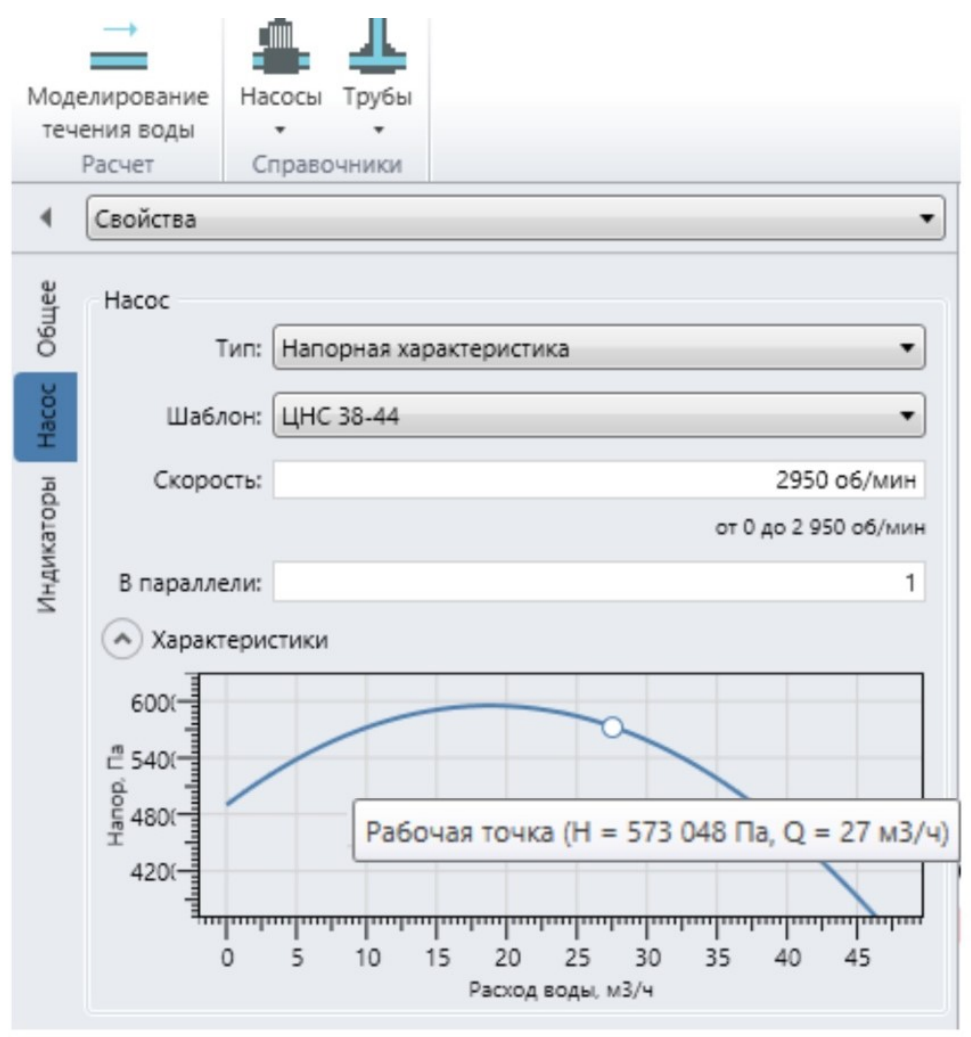

Рис. 4. Графическое отображение рабочей точки насоса на гидравлической характеристике

Расчет гидравлического сопротивления в программе «АэроСеть», как и в других отечественных и зарубежных программах, осуществляется согласно требованиям действующих нормативных документов. Как показывают исследования, расхождение в итоговых значениях гидравлических сопротивлений при выборе разных методик расчета незначительно и находится в пределах инструментальной погрешности $[12,13]$.

Гидравлическое сопротивление труб в программе «АэроСеть» рассчитывается на основе их внутреннего диаметра и длины. Для этого используется формула Шевелева [14] в основе которой лежит методика описанная в [14]:

$$
A=\frac{0.001735}{d^{5.3}} \cdot \rho \cdot \mathrm{g},
$$

где А - удельное гидравлическое сопротивление трубы, $\mathrm{H} \cdot \mathrm{c}^{2} / \mathrm{M}^{9} ; d$ - внутренний диа-

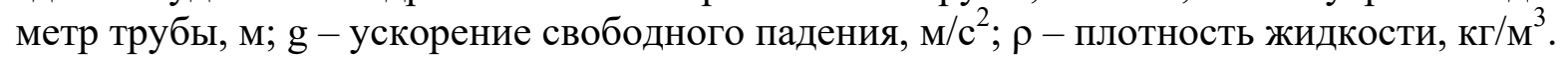

Согласно [13], формула (1) применима при средних скоростях движения воды более 1,2 м/с, поэтому при меньших скоростях движения воды к гидравлическому сопротивлению (1) вводится поправочный коэффициент, учитывающий неквадратичность зави- 
симости потерь напора от средней скорости движения воды и определяющийся выражением:

$$
K_{v}=0.852 \cdot\left(1+\frac{0.867}{v}\right)^{0.3}
$$

где $v$ - средняя по сечению скорость течения воды, м/с.

Полное гидравлическое сопротивление участка трубопровода с учетом местных сопротивлений затем вычисляется по формуле.

$$
R=A \cdot L \cdot\left(1+\frac{K_{\text {losses }}}{100}\right)
$$

где $R$ - полное гидравлическое сопротивление трубы, $\mathrm{H} \cdot \mathrm{c}^{2} / \mathrm{M}^{8} ; L$ - длина трубы, м; $K_{\text {losses }}$ - местные гидравлические сопротивления в трубе, \%.

Формулы (1)-(3) далее используются для численного решения системы уравнений Кирхгоффа I и II.

Численное решение системы уравнений Киргофа в программе «АэроСеть» осуществляется с помощью метода контурных расходов.

\section{Разработка технических решений}

Разработка технических решений для оптимизации работы системы трубопроводов, а также обеспечения нормативных показателей в ходе эксплуатации или на стадии проектирования начинается с определения требуемых расходов воды на конечных потребителях воды. В программе «АэроСеть» реализована возможность задания требуемого расхода на потребителях (рис. 5). Требуемые расходы можно сохранять в свойствах потребителей воды, а затем сравнивать с вычисленными модельными расходами. Кроме того, на схеме можно выделить цветом потребителей, у которых вычисленный расход воды оказался меньше требуемого. В случае дефицита воды можно путем моделирования определить оптимальные места установки повысительных насосных станций и определить параметры их работы.

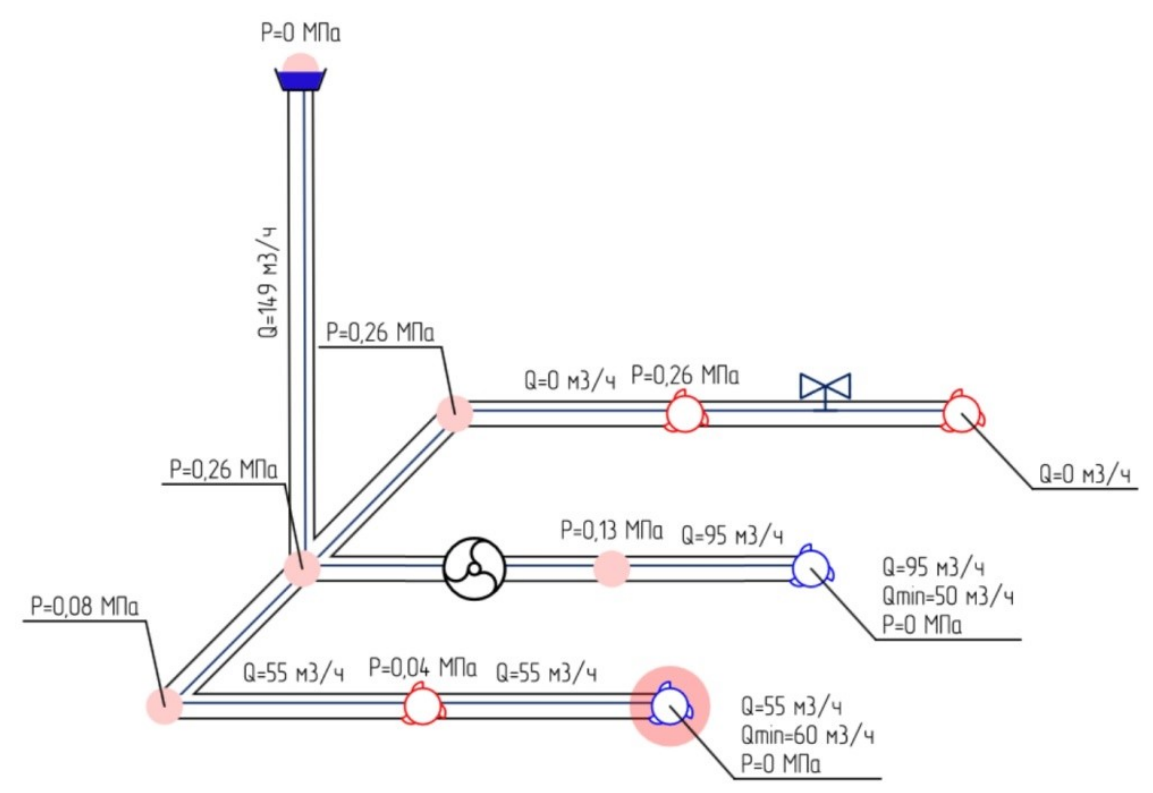

a)

б)

B)

Рис. 5. Инструменты графического анализа на примере упрощенной модели гидравлической сети:

(a) - отключение участков трубопровода, (б) - индикаторы обеспеченности потребителей требуемым расходом воды, (в) - вывод давлений в узлах сети трубопровода 
Также правилами безопасности предъявляются требования к максимальному давлению воды в трубопроводе на конечных потребителях которое должно находиться в диапазоне от 0,6 до $1,5 \mathrm{MПа}[14,15]$. Для проверки давления в программе «Аэросеть» имеется возможность отображения давления в узловых точках гидравлической сети (рис. 5). В случае превышения максимально допустимого давления в программе имеется возможность подбора регулирующих шайб, позволяющих снизить давление на конкретных участках.

В зависимости от местоположения потребителя имеется необходимость производить перераспределение воды в трубопроводе, для этого реализована возможность применения запорной арматуры на отдельных направлениях трубопровода. Это позволяет проводить быструю оценку перераспределения воды в системе в зависимости от сценария задействования (рис. 5).

Возможность быстрого пересчета всех параметров системы делает применение программы эффективным при анализе разветвлённых систем, содержащих большое количество ветвей. Скорость расчета сетей, количество ветвей которых исчисляется тысячами, составляет не более одной минуты. Такая скорость расчета позволяет производить сравнение различных вариантов. На данный момент программу «АэроСеть» для расчета противопожарных трубопроводов использует ряд крупных горнодобывающих предприятий: ЗФ ПАО «ГМК «Норильский никель», ПАО «Уралкалий», ОАО «Беларуськалий», АО «Фосагро».

\section{Заключение}

На примере программы «АэроСеть» показаны возможности современных программно-вычислительных комплексов для разработки моделей систем пожарно-оросительных трубопроводов шахт и рудников и дальнейшей работе с ними на всех этапах разработки технических решений по приведению данных систем к нормативным требованиям.

С учетом сложности топологий горных выработок и, соответственно, разветвленности сетей противопожарной защиты современных горнодобывающих предприятий применение программных инструментов при проведении моделирования и последующего анализа полученного решения является необходимой мерой, позволяющей снизить вероятность возникновения ошибок, связанных с человеческим фактором, а также сократить время, необходимое для разработки эффективных решений при проектировании или модернизации систем противопожарных трубопроводов в шахтах и рудниках.

\section{Исследование выполнено при финансовой поддержке Министерства науки и образования РФ в рамках согламения по государственному заданию № 075-03-2021-374 от «29» декабря 2020 г.}

\section{БИБЛИОГРАФИЧЕСКИЙ СПИСОК}

1. Мальцев С.В., Семин М.А., Кормщиков Д.С. Метод определения коэффициентов аэродинамического сопротивления шахтных стволов медно-никелевых рудников // Физико-технические проблемы разработки полезных ископаемых. - 2020. - № 6. - C. 170-178. - DOI: 10.15372/FTPRPI20200615.

2. Левин Л.Ю., Семин М.А., Зайцев А.В. Разработка математических методов прогнозирования микроклиматических условий в сети горных выработок произвольной топологии // Физико-технические проблемы разработки полезных ископаемых. - 2014. - № 2. - С. 154-161.

3. Левин, Л.Ю., Зайцев А.В., Бутаков С.В., Семин М.А. Нормализация микроклиматических условий горных выработок при отработке глубокозалегающих запасов калийных рудников // Горн. журн. 2018. - № 8. - С. 97-102. 
4. Цапенко Е.Ф., Шкундин С.З. Электробезопасность на горных предприятиях: Учеб. пособие. - 3 изд., стер. - М.: Изд-во МГГУ, 2008. - 103 с.: ил.

5. Zhang X., Guan Y., Fang Z., Liao Y. Fire Risk Analysis and Prevention of Urban Comprehensive Pipeline Corridor // Procedia Engineering. - 2016. - Vol. 135. - P. 463-468. - DOI:10.1016/j.proeng.2016.01.156.

6. Li-dong Wang, Hai-tao Sun, Hong Zhou, Fire risk analysis and fire safety design of comprehensive pipeline corridor in a community // Water and wastewater engineering. - 2015. - V. 41. - P. 66-68.

7. Vicente D.J., Garrote L., Sanchez R. and Santillan D. Pressure management in water distribution systems: Current status, proposals, and future trends // Journal of Water Resources Planning and Management. 2016. - V. 142, № 2. - Номер статьи 04015061. - DOI: 10.1061/(ASCE)WR.1943-5452.0000589.

8. Peng Y., Jiang Z. Optimization of underground mine water supply network // IOP Conference Series: Earth and Environmental Science. - 2019. - V. 300, № 2. - Номер статьи 022115. - DOI: 10.1088/1755$1315 / 300 / 2 / 022115$.

9. Аэросеть - Решение проблем рудничной вентиляции: [офиц. сайт]. - Текст электронный. - URL: http://aeroset.net. - (дата обращения: 17.05.2021).

10. Вентиляция 2: Программный комплекс: [офиц. сайт]. - Текст электронный. - URL: https://minesoft.ru.

11. VentSim: [офиц. сайт]. - Текст электронный. - URL: https://ventsim.com/ru/.

12. Сафина Л.Г., Махлаёв В.К. Сравнение различных формул для расчёта потерь напора по длине в трубах // Избранные доклады 62-й университетской науч.-техн. конф. студентов и молодых ученых. Томск, 2016. - C. 1347-1350.

13. Vaabel J., Koppel T., Sarv L., Annus I. Determination of Water Distribution Network Resistance Coefficient and Hydraulic Capacity // Procedia Engineering. - 2014. - V. 89. - P. 679-684. DOI:10.1016/j.proeng.2014.11.494.

14. Шевелев Ф.А., Шевелев А.Ф. Таблицы для гидравлического расчета водопроводных труб: справ. пособие. - 6-е изд., доп. и перераб. - М.: Стройиздат, 1984. - 117 с.

15. СП 31.13330.2012 Водоснабжение. Наружные сети и сооружения. Актуализированная редакция СНиП 2.04.02-84* с изменением № 1: утв. Минрегион России 29.12.2011. - М., 2015. - 132 с.

\title{
НОВЫЕ ПАРАДИГМАЛЬНЫЕ ПОДХОДЫ К УПРАВЛЕНИЮ ДИНАМИКОЙ ПЫЛЕВОЙ ОБСТАНОВКИ ПРИ МЕХАНИЗИРОВАННОЙ ДОБЫЧЕ КАЛИЙНОЙ РУДЫ
}

\author{
Г.З. Файнбург, А.Г. Исаевич \\ Горный институт УрО РАН, г. Пермь
}

\begin{abstract}
Аннотация: В статье рассматриваются новые парадигмальные подходы к управлению динамикой пылевой обстановки при механизированной добыче калийной руды, когда традиционные методы снижения концентрации пыли становятся неэффективными. Рассмотрены основные массообменные процессы, возникающие при проветривании горных выработок, и показаны некоторые особенности переноса пыли калийной соли при действии данных процессов. Обсуждены достоинства и недостатки нагнетательного и всасывающего способов проветривания применительно к калийным рудникам. Описаны результаты экспериментальных исследований всасывающего способа проветривания на руднике СКРУ-3.
\end{abstract}

Ключевые слова: калийная соль, аэрозоль, пыль, микрозонирование, зона дыхания, процесс вытеснения, процесс смешения.

\section{Введение}

Любая добыча полезных ископаемых, включая калийную руду, сопровождается разрушением сплошного массива и образованием целого спектра его фрагментов от негабарита при буровзрывной выемке через «щебенкообразную» руду комбайновых комплексов к пылевидным фракциям (не обогащаемым флотацией), которые содержат пылевидные частицы и более тонкодисперсный респирабельный аэрозоль [1]. 